\title{
Comparação de métodos para testar a citotoxicidade "in vitro" de materiais biocompatíveis
}

\section{Comparison of methods to test an "in vitro" test of cytotoxicity of biocompatible hospital materials}

\author{
Aurea Silveira Cruz, Cristina Adelaide Figueiredo, Tamiko Ichikawa Ikeda, Ana Claudia \\ Egydio Vasconcelos, Jakson Batista Cardoso e Luís Florêncio de Salles-G omes \\ Seção de Culturas Celulares do Instituto Adolfo Lutz. São Paulo, SP - Brasil
}

\begin{abstract}
Resumo
Objetivo

Comparar a sensibilidade do método de difusão em ágar e do método de extração utilizando as linhagens celulares RC-IAL (células fibroblásticas de rim de coelho) e HeLa (células epiteliais de carcinoma do colo do útero humano), na avaliação da citotoxicidade "in vitro" de materiais de uso médico-hospitalar.

Material e Método

Resultados

Conclusão

Foram testadas 50 amostras escolhidas por sorteio, entre as já conhecidamente positivas e negativas e identificadas como: algodão, espuma, borracha, látex, celulose e acrílico. Além, das amostras citadas foram testadas experimentalmente várias concentrações de SDS (duodecil sulfato de sódio) nas culturas celulares RC-IAL e HeLa.

Das 50 amostras testadas , 44 (88\%) foram positivas para os dois métodos. Mas quando comparado o SDS nos dois métodos foram observados resultados positivos nas concentrações de 0,5 a $0,05 \mu \mathrm{g} / \mathrm{ml}$ no método de difusão em ágar e no método de extração somente foi observado efeito citotóxico até a concentração de $0,25 \mu \mathrm{g} / \mathrm{ml}$.

Os resultados encontrados são similares aos observados por outros autores que testaram materiais como, por exemplo, ligas metálicas. Quando foi usado o SDS observou-se, nas duas linhagens celulares, diferenças favoráveis ao método de difusão em ágar em duas concentrações, isto é, a sensibilidade deste método foi significantemente maior, por inspecção, em relação ao método de extração, além de se constituir em método mais simples de ser realizado.
\end{abstract}

Objective
Cultura de células. Materiais biocompatíveis. Testes de toxicidade.

\section{Abstract}

A comparison of the sensitivity of the agar diffusion method with that of extraction using cell-lines RC-IAL (fibroblastic of rabbit kidney) and HeLa (epithelial carcionoma cells from the cervix uteri of the humam uterus), in the in vitro evaluation of materials of medical and hospital.

Correspondência para/Correspondence to: Aurea Silveira Cruz - Av. Dr. Arnaldo, 355 - 01246-902 São Paulo, SP - Brasil. Fax: (011) 853.3505 
Material and Methods

Results

Conclusion
Fifteen samples chosen at random, from among the already known positives and negatives in our stock, were tested and identified as cotton, form, latex, cellulose and acrylic. Besides the samples mentioned, many SDS (GIbco) concentrations were tested experimentally in RC-IAL and HeLa cell cultures.

Of the 50 samples tested, 44 (88\%) were positive by both methods. However, when the SDS were compared by using the two methods, positive results were noted in the concentrations of from 0.5 to $0.05 \mu \mathrm{g} / \mathrm{ml}$ in the agar diffusion ans extraction methods. A cytotoxic effect was only noted in the concentrations of up to $0.25 \mu \mathrm{g} / \mathrm{ml}$.

When the SDS was used, differences favorable to the agar diffusion method were observed in the two cell lines, in two concentrations; that is, the sensitivity of this method was quantitatively greater on inspection than that of the extraction method, as well as being the simpler method to use.

Cell-culture. Biocompatible materials. Toxicity tests.

\section{INTRO DUÇÃO}

O desenvolvimento dos testes de citotoxicidade "in vitro" e seu reconhecimento pelos órgãos internacionais como "Food and Drug Admnistration", em 1993 e "Organization for Economic Cooperation and Development", em $1987^{10}$ tem favorecido a substituição dos ensaios que utilizam animais de laboratórios.

Vários métodos "in vitro" que utilizam culturas celulares têm sido padronizados para avaliação da toxicidade de biomateriais, tais como: método de difusão em ágar ${ }^{6,13}$, método de extração ${ }^{13,14}$, método de contato direto ${ }^{2,9,15}$, método de inibição metabóli$\mathrm{ca}^{15,16}$, além dos métodos enzimáticos ${ }^{12}$.

No Instituto Adolfo Lutz (IAL), o método de difusão em ágar indicado pela Farmacopéia Americana (USP XXIII) ${ }^{13}$ tem sido amplamente utilizado para avaliação da citotoxicidade "in vitro" de numerosos materiais médico-hospitalares que entram em contato direto ou indireto com o ser humano.

O objetivo do presente trabalho, foi comparar a sensibilidade do método já utilizado no IAL com método de extração também indicado pela USP $\mathrm{XXIII}^{13}$. Para esta avaliação foram utilizadas, como substrato, duas linhagens celulares RC-IAL (linhagem de células fibroblásticas de rim de coelho) e HeLa (linhagem de células epiteliais de carcinoma de colo de útero humano), que após estudos realizados $^{6,7}$ foram eleitas por apresentarem maior sensibilidade nos testes de citotoxicidade "in vitro".

\section{MATERIAL E MÉTO DO}

\section{Amostras}

Foram testadas 50 amostras escolhidas por sorteio entre as já conhecidamente positivas e negativas do estoque do IAL, identificadas como algodão, espuma, borracha, látex, celulose e acrílico, todas enviadas pelas indústrias locais para avaliação da citotoxidade "in vitro".

No método de difusão em ágar, as amostras foram recortadas em tamanhos aproximados de $5 \mathrm{~mm}^{2}$ e colocadas diretamente sobre a camada de ágar. No método de extração foi utilizado 0,2g da amostra/mL de meio de Eagle sem soro.

As amostras para o método de difusão em ágar não sofreram qualquer tipo de tratamento, mas para o método de extração as amostras foram esterilizadas em autoclave a $121^{\circ} \mathrm{C}$, durante 15 min., com o objetivo de evitar a contaminação por bactérias e fungos durante o processo de extração.

Além das amostras citadas foram testadas, experimentalmente, várias concentrações de uma substância conhecidamente tóxica denominada duodecil sulfato de sódio (SDS- Gibco) ${ }^{5}$. As concentrações utilizadas foram de 0,$5 ; 0,25 ; 0,1 ; 0,05$ e $0,01 \mu \mathrm{g} / \mathrm{mL}$ preparadas em meio de Eagle sem soro. No método de difusão em ágar as diluições foram preparadas e embebidas em discos de papel de filtro atóxico com $5 \mathrm{~mm}$ de diâmetro de maneira que cada disco continha as concentrações finais de 0,$5 ; 0,25$; 0,$1 ; 0,05$ e $0,01 \mu \mathrm{g} /$ disco da substância.

Como controle positivo para ambos os métodos, foram utilizados fragmentos de látex, conhecidamente tóxicos; como controle negativo para o método de difusão em ágar foi utilizado papel de filtro atóxico e para o método de extração o meio mínimo de Eagle sem soro. A análise de 
cada amostra foi feita em duplicata no método de difusão em ágar e quadruplicata no método de extração.

\section{Culturas Celulares}

Foram utilizadas duas linhagens celulares: HeLa (ATCC-CCL-2) ${ }^{1}$ e RC-IAL ${ }^{8}$ isolada e mantida no IAL. As linhagens celulares foram cultivadas em meio mínimo de Eagle (MME) com 10\% de soro fetal bovino inativado (SFB), sem antibiótico e incubadas a $37^{\circ} \mathrm{C}$. Para a dispersão do tapete celular foi utilizada uma associação de tripsina $0,20 \%$ e versene $0,02 \%{ }^{11}$.

\section{Método de Difusão em Ágar}

Volumes de $5 \mathrm{~mL}$ de suspensão das linhagens celulares RC-IAL e HeLa foram semeados separadamente em placas de Petri de 50mm, na concentração de $1,5 \times 10^{5}$ células/mL em MME com $10 \%$ de SFB e incubadas durante $48 \mathrm{~h}$ a $37^{\circ} \mathrm{C}$ em estufa com ambiente de $5 \%$ de $\mathrm{CO}_{2}$. Em seguida, o meio líquido era descartado e o meio sólido ("overlay") era adicionado sobre o tapete celular. Este meio é composto de partes iguais de meio de Eagle, duas vezes concentrado, e ágar (Bacto-Difco) a 1,8\% contendo $0,01 \%$ de vermelho neutro como corante vital. No momento do uso, o ágar era fundido e misturado em proporções iguais com o meio de Eagle duas vezes concentrado, ambos à temperatura de $44^{\circ} \mathrm{C}$ e $5 \mathrm{~mL}$ desta mistura era adicionado às placas de cultura.

Antes que a camada de ágar solidificasse completamente, as amostras eram colocadas no centro da placa de Petri, e após o completo endurecimento do meio sólido as placas foram incubadas a $37^{\circ} \mathrm{C}$ em ambiente de $5 \%$ de $\mathrm{CO}_{2}$, na posição invertida. As leituras das placas inoculadas foram feitas macroscopicamente, onde a presença da citoto-xicidade era constatada por halo claro ao redor do material tóxico correspondente às células mortas e microscopicamente para as alterações morfológicas das células circundando a amostra. Quando presente, os diâmetros dos halos resultantes do efeito citotóxico eram cuidadosamente medidos usando régua milimétrica.

\section{Método de Extração}

Volume de $1 \mathrm{~mL}$ da suspensão das linhagens celulares RC-IAL e HeLa foram semeadas em tubos de ensaio na concentração de $1,5 \times 10^{5}$ células/mL em meio MME com $10 \%$ de $\mathrm{SBF}$ e incubadas por $48 \mathrm{~h}$ a $37^{\circ} \mathrm{C}$. Enquanto isso, as extrações das amostras foram processadas a $37^{\circ} \mathrm{C}$ por $24 \mathrm{~h}$, de acordo com a USP XXIII ${ }^{13}$. Depois da monocamada celular estar formada, o meio de crescimento dos tubos de cultura foi descartado e os meios contendo as extrações foram inoculados. Os tubos foram novamente incubados por $24 \mathrm{~h} \mathrm{a} 37^{\circ} \mathrm{C}$ e, após este período foram examinados ao microscópio óptico invertido e o grau de citotoxicidade do material foi determinado pela destruição das células em percentagem relacionada aos tubos de células controles.

\section{RESU LTAD OS}

Os resultados da comparação dos métodos de extração e o de difusão em ágar utilizando cinco diferentes concentrações de SDS contendo 0,$5 ; 0,25 ; 0,1$; 0,05 e $0,01 \mu \mathrm{g} / \mathrm{mL}$ pode ser observado na Tabela 1 . Foi constatado que as duas linhagens celulares no método de difusão em ágar apresentou efeito citotóxico frente às concentrações de $0,5 \mathrm{a} 0,05 \mu \mathrm{g} / \mathrm{mL}$, somente não apresentando halo de citotoxicidade na menor concentração usada no teste $(0,01 \mu \mathrm{g} / \mathrm{mL})$. Pelo método de extração, só foi observado efeito citotóxico até a concentração de $0,25 \mu \mathrm{g} / \mathrm{mL}$, nas duas linhagens usadas.

As 50 amostras testadas pelo método de difusão em ágar, das quais 44 (88\%) foram positivas, isto é, apresentaram efeito citotóxico caracterizado pela formação de halo claro ao redor do material testado, como pode ser observado nas Tabela 2 e Figura 1. Todas as 44 amostras foram positivas para as duas linhagens celulares usadas, com exceção de seis amostras de números $1.449,1.543,1.340,1.471$,

Tabela 1 - Comparação da sensibilidade de dois métodos frente a diferentes concentrações de duodecil sulfato de sódio (SD S) em duas linhagens celulares utilizadas.

Table 1 - Comparison of the sensitivity of the agar diffusion and extraction methods using various SDS concentration.

\begin{tabular}{|c|c|c|c|c|}
\hline \multirow[t]{2}{*}{$\begin{array}{l}\text { Diluições de SDS } \\
\text { em } \mu \mathrm{g} / \mathrm{ml}\end{array}$} & \multicolumn{2}{|c|}{$\begin{array}{l}\text { Medida do diâmetro do halo }(\mathrm{mm}) \text { de } \\
\text { citotoxicidade no método de difusão em ágar }\end{array}$} & \multicolumn{2}{|c|}{$\begin{array}{l}\text { Medida em (+) da toxicidade } \\
\text { no método de extração* }\end{array}$} \\
\hline & RC-IAL & HeLa & RC-IAL & Hela \\
\hline 0,5 & 35 & 35 & $4+$ & $4+$ \\
\hline 0,25 & 15 & 12 & $3+$ & $3+$ \\
\hline 0,1 & 15 & 10 & 0 & 0 \\
\hline 0,05 & 10 & 10 & 0 & 0 \\
\hline 0,01 & 0 & 0 & 0 & 0 \\
\hline \multicolumn{5}{|c|}{$* 4+=100 \%$ de citotoxicidade } \\
\hline \multicolumn{5}{|c|}{$\begin{array}{l}\begin{array}{l}3+ \\
2+\end{array}=55 \% \text { de citotoxicidade } \\
1+=25 \% \text { de citotoxicidade } \\
1+=\text { de citotoxicidade } \\
0=\text { ausência de citotoxicidade } \\
\text { RC }- \text { IAL (células fibroblásticas de rim de coelho) } \\
\text { HeLa (células epiteliais de carcinoma do colo do útero }\end{array}$} \\
\hline
\end{tabular}


$1.521,1.525$, já conhecidas como negativas e que não apresentaram efeito citotóxico.

Entre as amostras positivas foram verificadas algumas variações resultantes na medida dos diâmetros dos halos formados: 15 amostras $(34,1 \%)$ apresentaram maior diâmetro do efeito citotóxico quando a linhagem celular foi a RC-IAL. As amostras restantes $(65,9 \%)$ apresentaram diâmetro igual nas duas linhagens celulares utilizadas. A média dos diâmetros dos halos obtidos nas amostras nas duas linhagens celulares mostrou para a linhagem RC-IAL valor de 17,29mm e na linhagem HeLa 14,65mm. A diferença entre as médias dos diâmetros encontrada nas linhagens foi de 2,64 $\mathrm{mm}$.

A Tabela 2 mostra os resultados da avaliação da citotoxicidade das mesmas 50 amostras pelo método de extração. As 44 amostras positivas apresentaram efeito tóxico para ambas as linhagens celulares RC-IAL (Figura 2) e HeLa, com exceção das 6 amos-

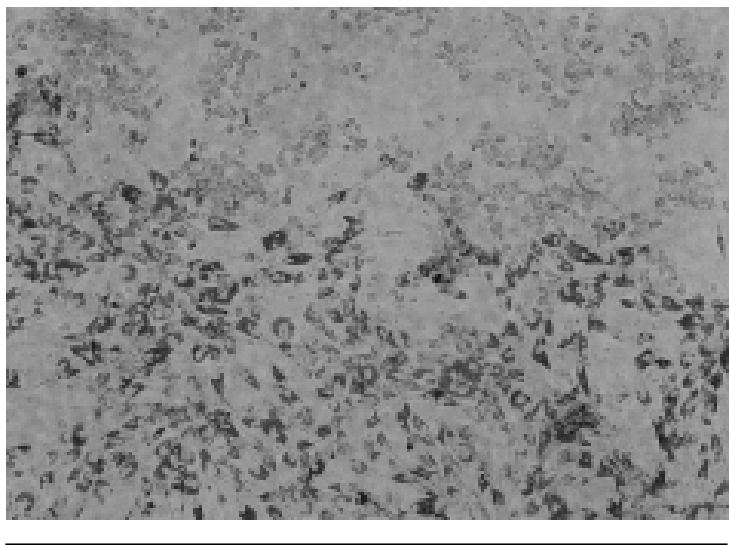

Figura 1 - M onocamada da linhagem celular RC-IAL no método de difusão em ágar apresentando efeito citotóxico caracterizado pela presença de halo claro formado por células mortas que não absorveram o corante vital (100x).

Figure 1- Monolayer of cell line RC-IAL in the agar diffusion method showing the cytotoxic effect as a clear halo formed by dead cells without the vital dye (100x).

tras negativas, portanto $88 \%$ positivas. Alguns materiais (13 amostras) apresentaram maior efeito tóxico para a linhagem celular RC-IAL $(29,55 \%)$. As demais amostras apresentaram efeito tóxico igual para as duas linhagens celulares $(70,45 \%)$.

A linhagem celular RC-IAL apresentou maior sensibilidade frente aos materiais testados em ambos métodos usados (Tabela 2), pois foi observado maior efeito citotóxico, isto é, maior halo de difusão (mm) ou maior percentagem de células mortas (+) quando comparado aos resultados obtidos com a linhagem celular HeLa, confirmando outros resultados obtidos anteriormente $e^{6,7}$.

Achado semelhante, maior halo também foi observado quando experimentalmente foram testadas diferentes concentrações de SDS nas duas linhagens celulares utilizadas porém, somente foi observado no método de difusão em ágar nas concentrações de 0,25 e $0,1 \mu \mathrm{g} / \mathrm{ml}$ de SDS.

Quando analisados os resultados dos dois métodos utilizados, frente às 50 amostras testadas (Tabela 2), não foi constatado diferenças de sensibilidade entre eles. Mas quando foram avaliadas as diferentes concentrações do SDS, pelos dois métodos, foi observado que o método de difusão em ágar detectou citotoxicidade em concentrações menores do produto avaliado, permitindo inferir que o método de difusão em àgar é mais sensível em relação ao método de extração quando foi usado o SDS, experimentalmente, isto é, em concentrações estritamente iguais sem qualquer variação eventual ocorrida pelo tamanho das amostras testadas.
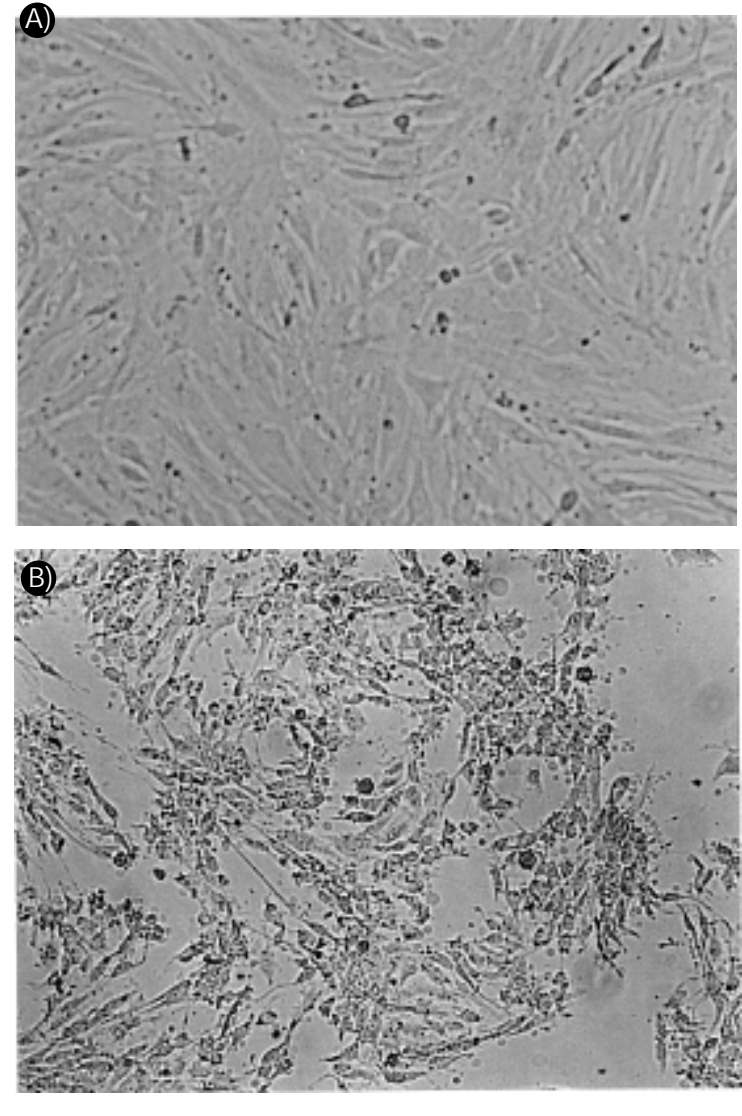

Figura 2 -

A- Monocamada normal da linhagem celular RC-IAL (100X). B - M onocamada da linhagem celular RC-IAL apresentando células degeneradas pelo efeito tóxico no método de extração (100 X).

\section{Figure 2 -}

A- Normal monolayer of the cell line RC-IAL (100 X). $B$ - Monolayer of cell line RC-IAL showing degenerated cells because of the toxic effect of the extraction method (100 X). 
Tabela 2 - Avaliação de citotoxicidade "in vitro"pelos métodos de difusão em ágar e extração.

Table 2 - "In vitro" cytotoxicity evaluation by agar diffusion and extraction methods.

\begin{tabular}{|c|c|c|c|c|c|}
\hline \multirow{3}{*}{ M aterial testado } & \multirow{3}{*}{ Amostra(N) } & \multicolumn{2}{|c|}{$\begin{array}{l}\text { M étodo de difusão em ágar } \\
\text { em duas linhagens celulares }\end{array}$} & \multicolumn{2}{|c|}{$\begin{array}{c}\text { M étodo de extração } \\
\text { em duas linhagens celulares }\end{array}$} \\
\hline & & \multicolumn{2}{|c|}{$\begin{array}{l}\text { M édia do diâmetro }(\mathrm{mm}) \text { do halo de } \\
\text { toxicidade nas placas de culturas celulares }\end{array}$} & \multicolumn{2}{|c|}{$\begin{array}{c}\text { M édia da toxicidade em } \\
\text { (+) nos tubos com culturas celulares }\end{array}$} \\
\hline & & RC-IAL & HeLa & RC-IAL & HeLa \\
\hline \multirow{5}{*}{ Algodão } & 500 & 10 & 10 & $3+$ & $2+$ \\
\hline & 871 & 15 & 10 & $4+$ & $3+$ \\
\hline & 919 & 10 & 10 & $4+$ & $4+$ \\
\hline & 920 & 05 & 05 & $4+$ & $3+$ \\
\hline & $\begin{array}{r}934 \\
1.040\end{array}$ & $\begin{array}{l}05 \\
40\end{array}$ & $\begin{array}{l}05 \\
15\end{array}$ & $\begin{array}{l}4+ \\
4+\end{array}$ & $\begin{array}{l}4+ \\
4+\end{array}$ \\
\hline \multirow{14}{*}{ Espuma } & 517 & 05 & 05 & $4+$ & $3+$ \\
\hline & 678 & 05 & 05 & $3+$ & $2+$ \\
\hline & 1.047 & 05 & 05 & $2+$ & $2+$ \\
\hline & 1.083 & 20 & 15 & $4+$ & $3+$ \\
\hline & 1.084 & 25 & 12 & $3+$ & $3+$ \\
\hline & 1.085 & 15 & 15 & $4+$ & $4+$ \\
\hline & 1.129 & 10 & 10 & $2+$ & $2+$ \\
\hline & 1.131 & 15 & 12 & $2+$ & $2+$ \\
\hline & 1.137 & 10 & 07 & $2+$ & $2+$ \\
\hline & 1.140 & 15 & 10 & $2+$ & $2+$ \\
\hline & 1.141 & 05 & 05 & $2+$ & $2+$ \\
\hline & 1.142 & 10 & 10 & $3+$ & $3+$ \\
\hline & 1.449 & 0 & 0 & 0 & 0 \\
\hline & 1.543 & 0 & 0 & 0 & 0 \\
\hline \multirow{12}{*}{ Borracha } & 731 & 18 & 18 & $4+$ & $3+$ \\
\hline & 737 & 40 & 40 & $3+$ & $3+$ \\
\hline & 743 & 05 & 05 & $3+$ & $3+$ \\
\hline & 776 & 35 & 30 & $4+$ & $3+$ \\
\hline & 1.313 & 10 & 10 & $2+$ & $2+$ \\
\hline & 1.387 & 30 & 30 & $4+$ & $1+$ \\
\hline & 1.392 & 25 & 25 & $4+$ & $4+$ \\
\hline & 1.393 & 25 & 25 & $4+$ & $4+$ \\
\hline & 1.468 & 30 & 30 & $4+$ & $4+$ \\
\hline & 1.561 & 25 & 25 & $4+$ & $4+$ \\
\hline & 1.564 & 15 & 15 & $4+$ & $3+$ \\
\hline & 1.585 & 25 & 25 & $4+$ & $4+$ \\
\hline \multirow{8}{*}{ Látex } & 599a & 15 & 10 & $4+$ & $4+$ \\
\hline & $599 b$ & 15 & 15 & $4+$ & $4+$ \\
\hline & 693 & 10 & 10 & $3+$ & $2+$ \\
\hline & 1.015 & 20 & 17 & $4+$ & $3+$ \\
\hline & 1.138 & 25 & 25 & $4+$ & $4+$ \\
\hline & 1.294 & 25 & 25 & $4+$ & $4+$ \\
\hline & 1.337 & 25 & 25 & $4+$ & $4+$ \\
\hline & 1.540 & 25 & 25 & $4+$ & $3+$ \\
\hline \multirow{3}{*}{ Celulose } & 965 & 15 & 12 & $3+$ & $3+$ \\
\hline & 1.030 & 13 & 10 & $4+$ & $4+$ \\
\hline & & & & & \\
\hline \multirow{7}{*}{ Acrílico } & 893 & 15 & 10 & $2+$ & $2+$ \\
\hline & 952 & 05 & 05 & $4+$ & $4+$ \\
\hline & 1.044 & 35 & 30 & $2+$ & $2+$ \\
\hline & 1.340 & 0 & 0 & 0 & 0 \\
\hline & 1.471 & 0 & 0 & 0 & 0 \\
\hline & 1.521 & 0 & 0 & 0 & 0 \\
\hline & 1.525 & 0 & 0 & 0 & 0 \\
\hline Papel de filtro & Controle - & 0 & $M$ & e s/soro & 0 \\
\hline Látex & Controlet & 35 & 35 & $4+$ & $4+$ \\
\hline
\end{tabular}




\section{DISCU SSÃO}

$\mathrm{Na}$ literatura especializada existem poucos estudos realizados com relação à sensibilidade comparativa entre estas duas metodologias, em especial quando se trata da avaliação de produtos de uso médico-hospitalar ${ }^{3}$. Como rotineiramente esta avaliação é realizada no IAL, houve interesse em verificar se o método de difusão em ágar apresenta ou não maior ou menor sensibilidade.

Além disso, não foi encontrado na literatura nacional qualquer trabalho que utilize o método de extração para avaliação da citotoxicidade "in vitro" em materiais de uso médico-hospitalares, solicitados rotineiramente pela indústria nacional.

No presente estudo foram obtidos alguns resultados interessantes, pois quando foram avaliadas as 50 amostras enviadas, não se observaram diferenças na sensibilidade entre os dois métodos estudados. Houve, portanto, inteira concordância dos métodos, evidenciada pelos resultados obtidos na prática.

Os resultados do presente trabalho, quando usados os dois métodos nos 50 materiais testados, são similares aos encontrados por outros autores ${ }^{4}$ quando testaram ligas metálicas para verificação da citotoxicidade, ainda que a verificação no trabalho citado era avaliada pelo crescimento das células junto das substâncias testadas. Esses citados autores consideram que o método de difusão em ágar é ótimo para detectar os efeitos diretos e de extração; acreditam ainda, que o uso de ágar poderia representar um fator que modificaria a interação do material a ser testado com as células usadas. Este fato, também é comentado por outros autores que relatam a dificuldade de materiais não solúveis difundirem através do ágar³

A diferença de comportamento (Tabela 1) em favor da maior sensibilidade das linhagens celulares RC-IAL e HeLa, sobre estas mesmas linhagens na presença dos extratos, demonstrou que quando foi usado o SDS a diferença foi de duas concentrações, isto é, foi quantitativamente significativa por simples inspeção, indicando claramente a maior sensibilidade do método de difusão em ágar sobre o método de extração em condições experimentais. Não é possível generalizar o resultado de maior sensibilidade entre os métodos na detecção de toxicidade baseado somente em uma determinada substância, necessitando, portanto, a experiência com outros produtos tóxicos, em maior número, para afirmação do ocorrido.

Entretanto, em trabalho anterior ${ }^{7}$, foi manifestado, pelos resultados obtidos em pequeno (7) e grande (562) número de amostras, o melhor desempenho da linhagem RC-IAL no método de difusão em ágar frente às linhagens celulares HeLa e MRC-5 (pulmão de feto humano) e, experimentalmente, frente ao ácido ascórbico, outra substância conhecidamente tóxica.

Esta somatória de dados são importantes porque o método utilizado deve ser o mais sensível possível, para que tenha capacidade de detectar pequenas quantidades de produtos tóxicos que possam estar contidos nas matérias-primas usadas na confecção dos produtos que entram em contato com o ser humano.

O método de difusão em ágar, além de apresentar ótima sensibilidade, talvez seja o mais recomendado porque durante a sua execução não há necessidade do produto analisado sofrer qualquer processamento, ao contrário do método de extração, onde a amostra deve ser descontaminada por autoclave e ficar em estufa por $24 \mathrm{~h}$ a $37^{\circ} \mathrm{C}$ para que se processe a extração.

Concluiu-se que devem ser empregados na rotina de laboratório os dois métodos analisados no presente trabalho com os substratos celulares RC-IAL e HeLa para a determinação da citotoxicidade "in vitro"de materiais hospitalares. Esta seria a conduta recomendada, dentro das possibilidades do laboratório, para detectar menores níveis de toxicidade em materiais biocompatíveis. E isso tendo em vista, principalmente, o contato desses materiais com pessoas de saúde debilitada. 


\section{REFERÊNCIAS}

1. AMERICAN TYPE CULTURE COLLECTION. Catalogue of cell lines \& hybridomas. 5th ed. Rockville, 1992.

2. BANDO, B. M. \& ROSEBAUM, M. J. Toxicity in HeLa cells mediated by plastics wraps. Lab. Pract., 22:26-31,1973.

3. CELL culture test methods. Philadelphia, ASTM Committee F-4 on Medical and Surgical Materials and Divices. (ASTM Sp. Tech. Publ., 810), 1983.

4. CERVINKA, M.; PUZA, V.; HROCH, M.; CUVINKOVÁ,Z. In vitro cytotoxicity testing of metal alloys used in medicine comparison of different approaches. Toxicol. Vitro, 8: 783-5,1994.

5. CORNELIS, M.; DUPONT, C.H.; WEPIERRE, J. Prediction of eye irritancy potential of surfactants by cytotoxicity tests in vitro on cultures of human skin fibroblasts and keratinocytes. Toxicol. Vitro, 6:119-28, 1992.

6. CRUZ, A. S.; CUPPOLONI, K. M.; MARTINEZ, C. H. O.; SALLES-GOMES, L. F. Culturas Celulares na detecção da toxicidade de materiais médico-hospitalares e outros que entram em contato com o ser humano. Rev. Inst. Adolfo Lutz 47: $51-7,1987$

7. CRUZ, A. S.; FIGUEIREDO, C. A.; MARTINEZ, C. H. O.; SALLES-GOMES, L. F. Detecção da citotoxicidade de materiais biocompatíveis nas linhagens celulares MRC-5, HeLa e RC-IAL. Rev. Inst. Med. Trop. S.Paulo, 34:99105,1992 .

8. CRUZ, A. S.; FIGUEIREDO, C. A.; BARBOSA, M. L.;
MARTINEZ, C. H. O.; SALLES-GOMES, L. F. RC-IAL: Linhagem celular continua de rim de coelho: características e substrato para replicação de vírus. Rev. Saúde Pública, 26:392-9,1992.

9. GILL, M. Direct cell contact screening for materials and devices. Med. Device Diagn. Ind., 4: 72-6,1982.

10. HUGGET, A.C.; SCHILTER, B.; ROBERFROID, M.; ANTIGNAC, E.; KOEMAN, J. H. Comparative methods of toxicity testing. Food. Chem. Toxic., 34: 183-92,1996.

11. LENNETTE, E. H. \& SCHMIDT, N. J. Diagnostic procedures for viral, rickettsiae and chlamydia infections. 5th ed.Washington, American Public Health Association, 1979.

12. OHNO, T.; ITAGAKI, H.; TANAKA, N.; ONO, H Validation study on five different citotoxicity assay in Japan an Intermediate Report. Toxicol. Vitro, 9:571-6, 1995.

13. UNITED STATES PHARMACOPEIA. Rockville, Twinbrook Parkway, 1995. v.23 p.1697-99.

14. VASINGTON, P. J.; PIERSMA, H. D.; CORBETT, J. J.; BITTLE, J. L. Cytotoxicity of rubber closures in tissue culture systems. J. Pharm. Sci., 56:1276-9, 1967.

15. WENZEL, D. G. COSMA, G. N. A quantitative metabolic inhibition test for screnning toxic compunds with cultured cells. Toxicology, 29:173-82, 1983

16. WILLIAMS, G. M.; DUNKEL, V. C.; RAY, V. A. Cellular systems for toxicity. Ann. N. Y. Acad. Sci., 407:1-484, 1983. 